\title{
SISTEM PENGARSIPAN BERITA DI JAWA POS RADAR KUDUS
}

\author{
Evanita $^{1}$, Muhammad Ulin Nuha ${ }^{2}$ \\ 1,2 Program Studi Teknik Informatika, Fakultas Teknik, Universitas Muria Kudus \\ Email: ${ }^{1}$ evanita@umk.ac.id, ${ }^{2} 201751143 @ u m k . a c . i d ~$
}

(Naskah masuk: 27 Mei 2021, diterima untuk diterbitkan: 26 Juni 2021)

\begin{abstract}
Abstrak
Pengelolaan data Berita masih menggunakan sistem manual yaitu masih ditulis di buku dan disimpan hanya dalam file dan setiap 1 bulan sekali dihapus. Karenanya, perlu diadakan pembenahan yang teratur di dalam manajemen pengarsipan yang lebih baik lagi. Perangkat lunak tersebut merupakan sebuah sistem pengolahan data dan informasi pengarsipan yang menyediakan informasi berita atau surat kabar yang bagus dan tertata rapi dalam pengolahan data. Fitur yang tersedia dalam sistem tersebut adalah data perijin dan informasi pengarsipan dari masing-masing pemohon yang nantinya digunakan untuk membuat laporan pengarsipan yang lebih cepat dan akurat.
\end{abstract}

Kata kunci: Jawa Pos, Radar Kudus, Sistem Informasi, PHP, MySql

\section{NEWS ARCHIVING SYSTEM IN JAWA POS RADAR KUDUS}

\begin{abstract}
News data management still uses a manual system, which is still written in books and stored only in files and deleted once every 1 month. Therefore, it is necessary to make regular improvements in better records management. The software is a data processing system and archiving information that provides good news or newspaper information and is neatly organized in data processing. The features available in the system are licensing data and archiving information from each applicant which will later be used to make filing reports that are faster and more accurate.
\end{abstract}

Keywords: Jawa Pos, Radar Kudus, Information Systems, PHP, MySql

\section{PENDAHULUAN}

pengelolaan data Berita masih menggunakan sistem manual yaitu masih ditulis di buku dan disimpan hanya dalam file dan setiap 1 bulan sekali dihapus. Karenanya perlu diadakan pembenahan yang kompleks dan teratur didalam manajemen pengarsipan yang lebih baik lagi. Dipelukannya sistem untuk menghindari kesalahan atau kekeliruan yang terjadi pada saat mengelola data pengarsipan.

Pengarsipan adalah sitem informasi yang dapat mengelola data dengan mudah dan efisien. Sistem informasi ini dapat membantu untuk mengelola data pengarsipan berita secara cepat, mudah, dan akurat.

Arsip adalah kumpulan suatu dokumen yang disimpan secara teratur dan berencana karena memiliki fungsi agar setiap kali dibutuhkan bisa ditemukan kembali dengan cepat.
Kata arsip dalam bahasa Indonesia diambil dari bahasa Yunani archium yang artinya peti tempat untuk menyimpan sesuatu.

Pengertian arsip awalnya menunjukkan tempat atau ruang penyimpanan seperti database, namun saat ini pengertian arsip lebih sebagai catatan atau surat yang memiliki kegunaan untuk disimpan dengan sistem kearsipan.

Sedangkan dalam bahasa Latin, kata arsip disebut felum (bundle) yang berarti benang atau tali. Kala itu benang atau tali digunakan untuk mengikat kumpulan lembaran tulisan atau catatan agar ringkas dan mudah dicari jika diperlukan.

\section{Landasan Teori}

\subsection{Sistem}

Sistem adalah adalah bagian dari elemenelemen yang berkumpul dan berinteraksi untuk 
menyelesaikan masalah untuk mencapai tujuan. Dimana dapat digambarkan sebagai data, program, maupun algoritma, Sistem dibangun untuk meunjukkan efektifitas dan efisien sebuah komponen yang saling terintegrasi (Jogiyanto, 2005), (Prahasta, 2005).

\subsection{Manfaat Sistem}

a. Meningkatkan aksesibilitas data yang tersaji secara akurat bagi para pemakai

b. Tampilan yang sangat sederhana sehingga mudah digunakan bagi para pemakai

c. Menganstisipasi jika ada kerusakan dari pemakai dengan cara backup data

d. File yang tersimpan didatabase tidak terlalu besar

e. Terstruktur rapi dan mudah dicari oleh para pemakai

f. Data dijamin aman dibanding dengan system manual

g. Data bisa dirubah kapanpun bahkan bisa upload file dan download file di Aplikasi

\section{TINJAUAN PUSTAKA}

Beberapa penelitian terkait yang sebelumnya membahas mengenai pengelolaan arsip data ini. Hasil penelitian tersebut ditemukan dalam basis data jurnal online karena telah dipublikasikan yaitu antara lain :

1. "E-Arsip Berbasis Image Archives Management Process Model Untuk Meningkatkan Efektifitas Pengelolaan Arsip" hasil studi Robby Yuli Endra, Usman Rizal, dan Fenty Ariani yang dipublikasikan pada Jurnal EXPLORE Vol. 7, Nomor 1 Tahun 2016. Perubahan pengelolaan arsip dari metode manual hingga menggunakan metode digital. Sistem aplikasi yang dipakai ini dirancang dan dilengkapi dengan fitur notifikasi melalui sms, e-mail, dan sosial media lainnya.

2. Studi yang dilakukan oleh Sambas Ali Muhidin, Budi Santoso, dan Hendri Winata yang berjudul "Pengelolaan Arsip Digital" yang dipublikasikan pada Jurnal Pendidikan Bisnis dan Manajemen (JPBM) Vol. 2, Nomor 3, Tahun 2016. Penelitian ini berisi mengenai cara dan peralatan yang dibutuhkan dalam melakukan pengelolaan arsip secara digital melalui komputer atau handphone.

3. Studi oleh Rifauddin, M. yang berjudul "Pengelolaan Arsip Elektronik Berbasis Teknologi". Penelitian tersebut membahas pengaplikasian teknologi pada pengelolaan arsip digital yang ada di Indonesia.

4. Studi yang dilakukan oleh Habiburrahman yang berjudul "Penggunaan Perangkat Lunak Dalam Pengelolaan Arsip Konvensional Dan Elektronik" hasil penelitian tentang pengelolaan arsip dalam bentuk konvensional dan digital, dengan tujuan untuk mempermudah layanan kearsipan.

\section{HASIL DAN PEMBAHASAN}

\subsection{Perancangan Sistem}

Perancangan sistem merupakan salah satu pengembangan sistem. Berikut adalah perancangan Sistem yang menggunakan Data Flow Diagram (DFD). Berikut arus datanya dapat dilihat pada gambar 1 dan 2.

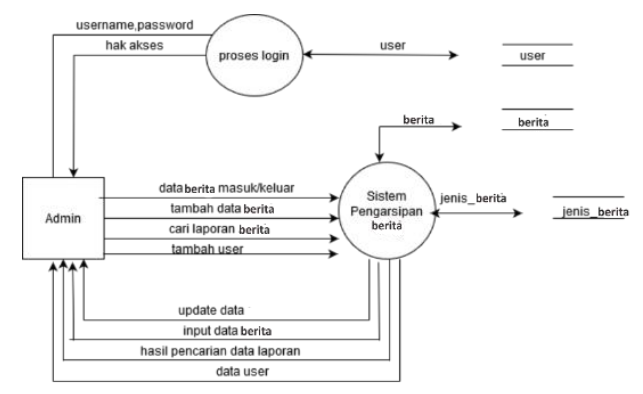

Gambar 1. DFD Level 0

Pada DFD level 0 ini membahas lebih rinci tentang arus data dari sistem pengarsipan berita dimana admin akan login serelah verifikasi pengguna atau user dan pasword. Admin dapat mengolah data setelah itu data akan tersimpan di database dan dapat dilihat kembali oleh admin. Di DFD level 0 ini harus sangat diperhatikan karena menyangkut alur program yang diciptakan. Kesalahan Perancangan sistem bisa terjadi karena DFD level 0 ini.

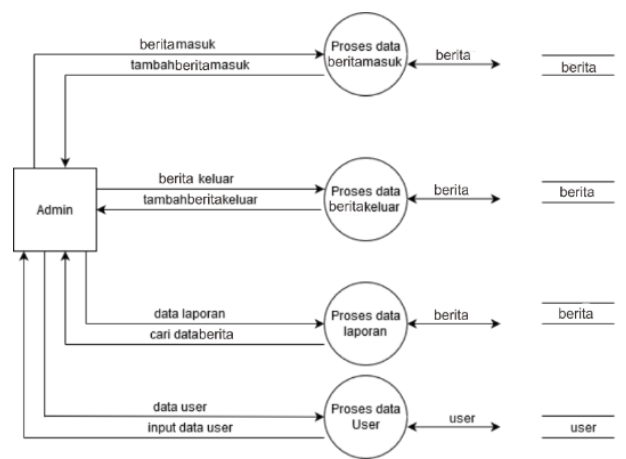

Gambar 2. DFD Level 1

Pada DFD level 1 ini admin dapat mengolah data berita berupa input data, edit data, maupun hapus data kemudian menyimpannya di database. Serta dapat menampilkan daftar user dan menginputkan data user.

\section{User Interface}


User Interface pada sistem ini dirancang secara comfortable agar pengguna nyaman dan tidak kesulitan dalam menggunakannya. Berikut adalah beberapa form pada sistem:

\section{a. Form menu Login}

Berisi tentang halaman login untuk masuk di aplikasi sebelum aplikasi digunakan dapat dilihat di gambar 3.

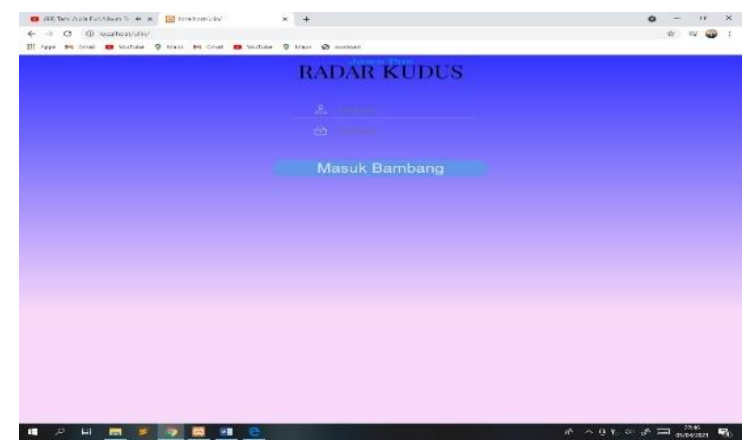

\section{Gambar 3. Form Menu Login}

Pada halaman utama hanya ada form login yang diharuskan mengisi user dan pasword yang telah terdaftar pada data user untuk bisa masuk di aplikasi ini, Tanpa pengisian data tersebut maka tidak akan bisa masuk di aplikasi.

\section{b. Form Menu Utama}

Berisi tentang menu utama yang dapat dipilih pada aplikasi. Berikut berbagai menu utama pada sistem. Form menu Home dapat dilihat di gambar 4.

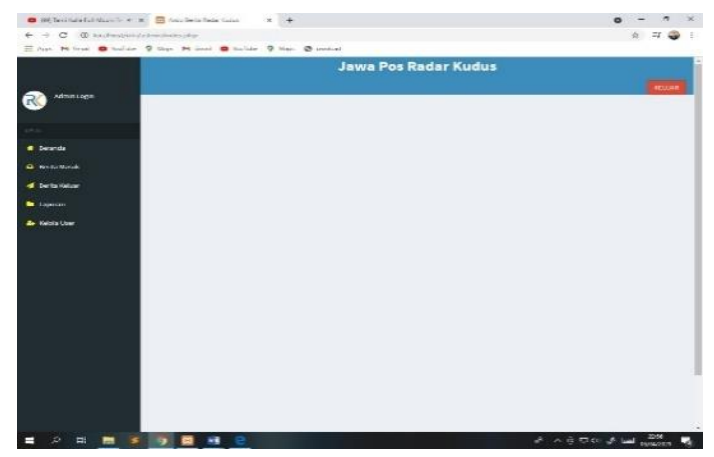

Gambar 4. Form Menu Home

Halaman utama terdapat setelah melakukan proses login pada form login. Pada form ini terdapat menu home,Berita Masuk, Berita Keluar, Laporan berita masuk, Laporan Berita Keluar, dan logout. Berikut form Berita Msuk dapat dilihat di gambar 5.

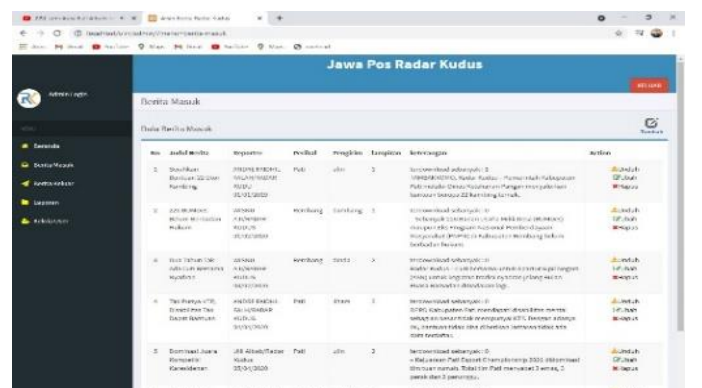

Gambar 5. Form Berita Masuk

Form Berita Masuk yaitu menampilkan data berita mulai dari no, index berita, nomor berita, perihal, pengirim, lampiran, keterangan, serta dilengkapi dengan fungsi edit, hapus data dan unduh data. Untuk menambah data berita masuk dengan klik tambah dipojok kiri atas. Form tersebut adalah Form Tambah Berita masuk dapat dilihat di gambar 6.

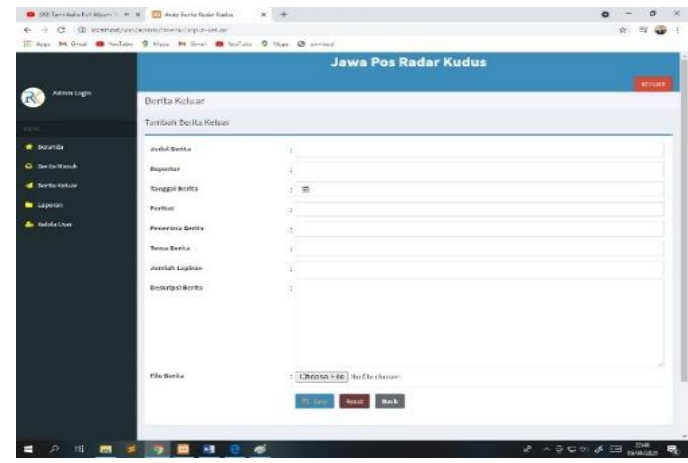

Gambar 6. Form Tambah Berita Masuk

Form Tambah Berita masuk yaitu mengisi data berita Masuk. Dilengkapi dengan file upload bukti berita yang berupa keterangan dan gambar. Selain berita masuk terdapat pula Form Berita Keluar yang dapat dilihat di gambar 7 .

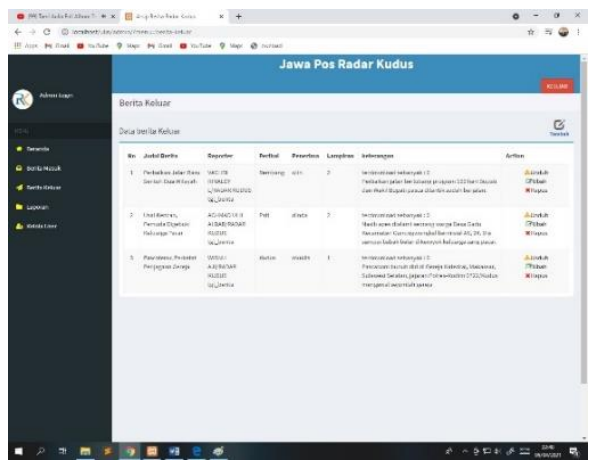

Gambar 7. Form Berita Keluar

Form Berita Keluar digunakan untuk melihat data berita keluar yang pengisiannya hamper sama dengan form Berita Masuk. Didalamnya juga dapat ditambahkan berita keluar. Form Tambah Berita Keluar dapat dilihat di gambar 8 . 


\section{Gambar 8. Form Tambah Berita Keluar}

Form Tambah Berita Keluar sama dengan tambah berita masuk yaitu mengisi data berita keluar. Dilengkapi dengan file upload bukti berita. Selain kedua form utama tersebut terdapat Form Kelola User yang dapat dilihat di gambar 9.

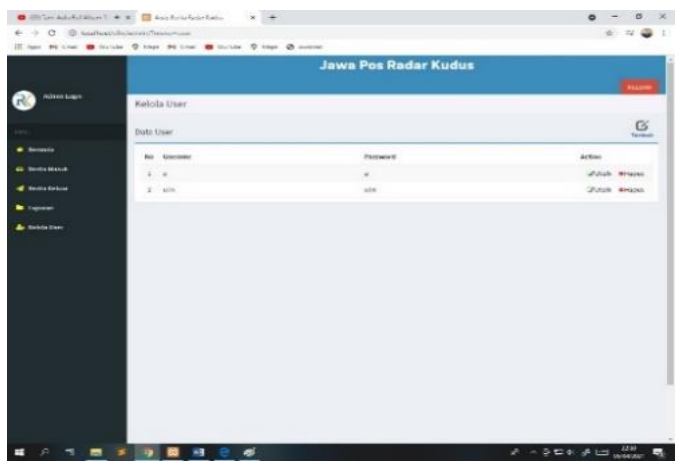

Gambar 9. Form Kelola User

Form Kelola User untuk melihat user dan dapat menambahkan, edit, hapus data user. Form Data User dapat dilihat pada gambar 10 .

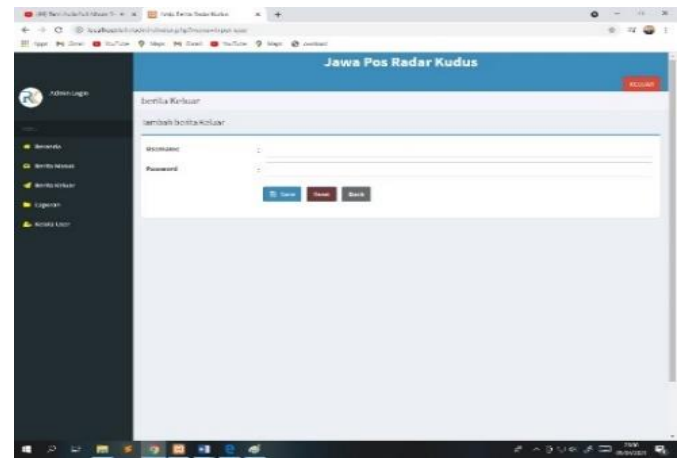

Gambar 10. Form Data User

Form data user yaitu untuk mengisi user dan pasword agar dapat mengakses sistem ini. Terdapat pula Form Data Laporan Berita Masuk dapat dilihat pada gambar 11 .

\section{Gambar 11. Form Data Laporan Berita Masuk}

Form laporan berita keluar yaitu untuk melihat data berita keluar dengan menggunakan tanggal dan tahun berita. Form Data Laporan Berita Keluar dapat dilihat di gambar 11.

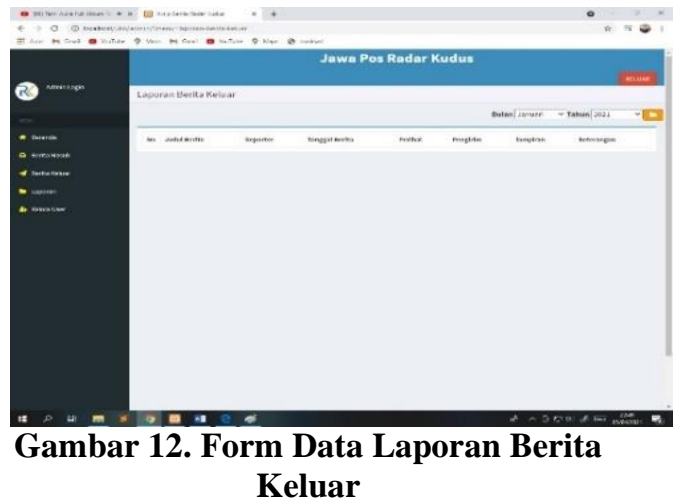

Form laporan berita keluar yaitu untuk melihat data berita keluar dengan menggunakan tanggal dan tahun berita.

\section{KESIMPULAN}

Sistem pengarsipan berita yang kebanyakan selama ini dilakukan secara manual perlu dirubah menjadi sitem digital agar mengikuti perkembangan zaman. Sistem ini memberi banyak kemudahan dalam melakukan pengelolaan arsip. Perkembangan perangkat lunak banyak tersedia sehingga dapat mengefektifkan pengelolaan arsip.

Manfaat dari sistem akan digunakan langsung oleh pihak instansi jawa pos radar kudus untuk pengolahan pengarsipan berita atau surat kabar, dan tidak hanya untuk pihak instansi jawa pos radar kudus namun bias digunakan buat instansi lain, seperti perpustakaan, arsip karyawan, arsip guru, arsip siswa dan sebagainya.

\section{DAFTAR PUSTAKA}

Jogiyanto, 2005, Analisis dan Disain Sistem Informasi, Andi Offset, Yogyakarta.

Robby, Usman, Fenty, 2016, E-Arsip Berbasis Image Archives Management Process Model Untuk Meningkatkan Efektifitas Pengelolaan Arsip, jurnal explore Vol 7. No 1.

Muhidin, Sambas Ali. Winata. Hendri. Santoso,

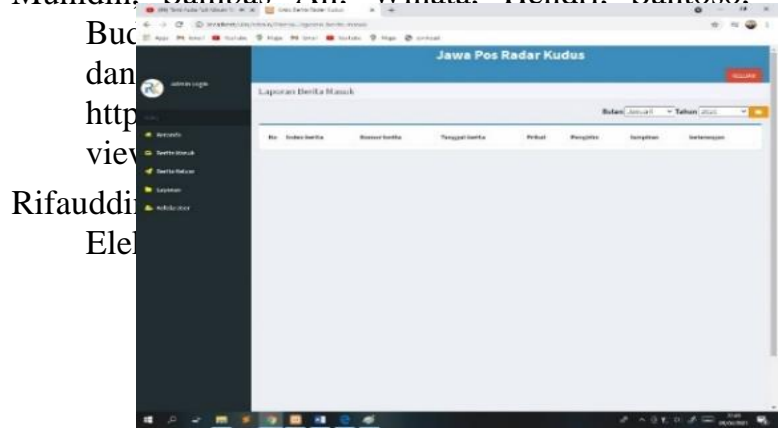


alHikmah : Jurnal Ilmu Perpustakaan, Informasi, dan Kearsipan Vol. 4, No. 2. DOI: 10.24252/ kah.v4i27

Habiburrahman, 2016, Penggunaan Perangkat Lunak Dalam Pengelolaan Arsip Konvensional Dan Elektronik, Vol $4 . \quad$ No 2. http://jurnal.uinsu.ac.id/index.php/jipi/article/d ownload/559/456 